\title{
ALTERNATIVA POTENCIAL PARA APROVEITAMENTO DO GLICEROL GERADO NA PRODUÇÃO DE BIODIESEL: SÍNTESE ENZIMÁTICA DE MONOLAURINA POR ESTERIFICAÇÃO
}

\author{
Larissa Freitas, Julio C. Santos, Marcos V. Barcza e Heizir F. de Castro* \\ Escola de Engenharia de Lorena, Universidade de São Paulo, CP 116, 12.602-810 Lorena - SP, Brasil
}

Recebido em 30/8/08; aceito em 27/5/09; publicado na web em 20/10/09

\begin{abstract}
POTENTIAL ALTERNATIVE FOR USING THE GLYCEROL GENERATED IN THE BIODIESEL PRODUCTION: ENZYMATIC SYNTHESIS OF MONOLAURIN BY ESTERIFICATION. Esterification reactions of glycerol with lauric acid in solvent free system were carried out using lipases from several sources. All lipases were immobilized on polysiloxane-polyvinyl alcohol particles by covalent binding with high activity recovered. Among the tested enzymes, the Candida antarctica lipase allowed to attain the highest molar conversion (76\%), giving similar proportions of monolaurin, dilaurin and low amount of trilaurin. To further improve the process, the Response Surface Methodology (RSM) was used and optima temperature and molar ratio glycerol to lauric acid were found to be $45{ }^{\circ} \mathrm{C}$ and 5:1, respectively. Under these conditions, $31.35 \%$ of monolaurin concentrations were attained and this result was in close agreement with the statistical model prediction.
\end{abstract}

Keywords: glycerol; lipase; factorial design.

\section{INTRODUÇÃO}

Monoglicerídeos (MAG) são surfatantes não iônicos que possuem o status GRAS (Generally Recognized as Safe) pela FDA (Food and Drugs Administration-USA), sendo amplamente utilizados nas indústrias farmacêuticas, de alimentos e de cosméticos, ${ }^{1}$ por não apresentarem efeitos colaterais quando ingeridos ou irritações na pele, ao contrário dos tensoativos iônicos. ${ }^{2}$ Tradicionalmente, estes compostos têm sido produzidos por via química pela glicerólise contínua de triglicerídeos empregando catalisadores inorgânicos $\left(\mathrm{Ca}(\mathrm{OH})_{2}, \mathrm{NaOH}\right)$ sob elevadas temperaturas $\left(220-250^{\circ} \mathrm{C}\right)^{3}$; no entanto, a síntese de MAG catalisada por lipases tem sido estudada intensamente como alternativa ao método clássico. ${ }^{4,5}$ As principais razões são a utilização de condições reacionais brandas, resultando em produtos de melhor qualidade, menores custos de energia e a seletividade das lipases. Além disso, a exploração da especificidade dessas enzimas possibilita a síntese de produtos que não poderiam ser obtidos por rota química convencional. Cabe ainda ressaltar que, do ponto de vista ambiental, o processo é tecnicamente limpo e seguro. ${ }^{6}$

Entre as rotas para a obtenção de monoglicerídeos, as reações enzimáticas empregando glicerol em esterificações (glicerol e ácidos graxos) e glicerólises (glicerol e óleos vegetais) possuem relevância adicional no atual contexto de prioridades nacionais, em função do estímulo do Governo Brasileiro à produção de biodiesel, a qual tem este poli-álcool como subproduto. Estima-se que, com o incentivo desta Política Nacional, a oferta atual do glicerol seja da ordem de 105 mil toneladas por ano (B3 - obrigatoriedade da adição de 3\% de biodiesel ao diesel, desde 01 de julho de 2008), e em 2013 (com o uso do B5) essa disponibilidade ficará em torno de 260 mil toneladas, ${ }^{7}$ tornando-se estritamente necessário o desenvolvimento de alternativas que permitam sua utilização, já que não há definida nesta política uma alternativa para absorver todo este volume de subproduto.

Monolaurina, produto alvo deste trabalho, é o principal monoglicerídeo produzido a partir de óleos láuricos. Em função de sua ocorrência natural no leite materno, em elevadas concentrações, estudos de aplicação terapêutica desse monoglicerídeo como um

*e-mail: heizir@dequi.eel.usp.br agente antiviral, bacteriano, protozoal e microbiano vêm sendo conduzidos com excelentes resultados. ${ }^{8}$ Como agente antimicrobiano, a monolaurina possui a capacidade de desestabilizar a camada lipídica de algumas bactérias (Listeria monocytogenes, Helicobacter pylori, Staphylococcus aureus e Streptococcus agalactiae) impedindo, assim, uma proliferação bacteriana. Candida albicans e Giardia lamblia são inativadas na presença da monolaurina, comprovando a sua ação antifúngica e protozoal. ${ }^{9}$ Com relação à sua ação antiviral, a monolaurina rompe a ligação do lipídeo com o vírus (ex: Measles virus, Herpes simples, Vírus da Influenza, pneumovírus e Vírus da rubéola), impedindo sua fixação às células hospedeiras inibindo, assim, a sua replicação e, consequentemente, prevenindo a infecção. ${ }^{9}$ Além disso, recentemente pesquisadores têm estudado a possibilidade da monolaurina combater o HIV (vírus que causa a AIDS), como também inibir o desenvolvimento do vírus e sua carga viral. Esta capacidade está aliada com o aumento da produção das células CD4 (células responsáveis pela defesa do organismo contra doenças infecciosas), que são as primeiras células atacadas pelo HIV. ${ }^{10}$

Com base neste contexto, o presente trabalho teve como objetivo sintetizar monoglicerídeos, especificamente, monolaurina a partir da reação de esterificação direta do glicerol com ácido láurico em sistema isento de solvente. Tais sistemas apresentam algumas vantagens, entre as quais se destacam: evita problemas de separação, de toxicidade e flamabilidade dos solventes orgânicos e, reduz o custo do produto final. Além disso, a eliminação de solventes é particularmente interessante nas indústrias alimentícias, onde existem rigorosas regulamentações para o seu uso. ${ }^{11}$

Inicialmente, lipases de diferentes fontes foram imobilizadas por ligação covalente em uma matriz híbrida e os derivados imobilizados resultantes foram testados na esterificação do glicerol com ácido láurico. A preparação de lipase mais efetiva foi utilizada em testes subsequentes, visando determinar a melhor combinação das variáveis temperatura e razão molar glicerol/ácido láurico para a obtenção máxima de monolaurina. Os experimentos foram realizados adotando a metodologia de planejamento estatístico, que possibilita verificar a influência das variáveis e suas interações no rendimento de um determinado processo com grande economia de tempo, material e recursos. ${ }^{12}$ 


\section{PARTE EXPERIMENTAL}

\section{Materiais}

Lipases de diferentes fontes, como Candida antarctica B (Calb L) e Thermomyces lanuginosa (Lipolase) gentilmente doadas pela Novozymes (Araucária, PR), pâncreas de porco (LPP) e Candida rugosa (LCR) (Tipos II e VII, Sigma Chemicals), Pseudomonas fluorescens (Lipase AK) e Burkholderia cepacia (Lipase PS), adquiridas da Amano Pharmaceuticals (Japão), foram utilizadas sem tratamento adicional. A preparação de lipase Novozym 435, disponível comercialmente na forma imobilizada (Novozymes, Brasil), foi também utilizada.

Como materiais de partida foram utilizados glicerol (Merck) e ácido láurico $\left(\mathrm{C}_{12}\right)$ (Riedel-de Haën), previamente desidratados com peneira molecular $0,32 \mathrm{~cm}$ de diâmetro (Silicato de sódio e alumínio) tipo $13 \mathrm{X}$-BHD Chemicals. Outros materiais foram: Tetraetil ortossilicato (TEOS), adquirido da Sigma-Aldrich Chemical; polietilenoglicol (PEG 1500, Synth); goma arábica em pó, pura (Synth). Todos os demais reagentes empregados foram de grau analítico.

\section{Imobilização da lipase em suporte híbrido}

O composto híbrido de polissiloxano-álcool polivinílico (POSPVA) foi sintetizado e ativado com glutaraldeído, conforme metodologia descrita por Paula et al.. ${ }^{13} \mathrm{~A}$ imobilização da lipase no suporte ativado consistiu do contato da enzima com o suporte $(250 \mathrm{mg} / \mathrm{g}$ suporte) juntamente com solução aquosa de $5 \mathrm{mg} / \mathrm{mL}$ de polietilenoglicol (MW 1500), por um período de $24 \mathrm{~h} \mathrm{a} 4{ }^{\circ} \mathrm{C}$. A lipase imobilizada foi recuperada por filtração a vácuo e o sistema imobilizado lavado com hexano. A atividade hidrolítica dos derivados imobilizados, determinada pelo método de hidrólise do paranitrofenilpalmitato, ${ }^{14}$ indicou uma recuperação satisfatória da enzima livre no suporte de imobilização (recuperação superior a 50\%).

\section{Ensaios de triagem da fonte de lipase mais adequada}

As sínteses foram realizadas em balões de fundo redondo (50 $\mathrm{mL}$ ), contendo misturas de glicerol e ácido láurico numa razão molar fixa de 3:1 e diferentes preparações de lipase numa proporção fixa de $2 \%(\mathrm{~m} / \mathrm{m})$ em relação à massa total dos reagentes. As reações foram conduzidas sob agitação magnética $(150 \mathrm{rpm})$ na faixa de temperatura entre 45 a $60^{\circ} \mathrm{C}$, dependendo da estabilidade térmica de cada preparação de lipase imobilizada. O progresso da síntese foi acompanhado pela retirada de alíquotas $(1 \mathrm{~mL})$, ao longo da reação e quantificado o teor de ácido láurico residual por titulometria empregando solução alcoólica de $\mathrm{KOH}$ 0,02M.

A conversão do substrato foi expressa em conversão molar do ácido láurico consumido, empregando a Equação 1.

$$
\text { Conversão molar } \%=\frac{C_{o}-C}{C_{o}} .100
$$

em que: $\mathrm{C}_{\mathrm{o}}=$ concentração inicial do ácido láurico e $\mathrm{C}=$ concentração do ácido láurico em um determinado tempo.

Nesta série de experimentos foram também calculados os valores de atividade de esterificação, produtividade e o rendimento por grama de catalisador, segundo descrito por Foresti e Ferreira. ${ }^{15}$

\section{Delineamento experimental}

Com base nos resultados obtidos, foi realizado um estudo do efeito das variáveis: temperatura $\left(\mathrm{x}_{1}\right)$ e razão molar entre glicerol e ácido láurico $\left(\mathrm{x}_{2}\right)$ com objetivo de determinar a melhor combinação dessas variáveis para a obtenção máxima de monolaurina. Um planejamento fatorial $2^{2}$ completo com 2 experimentos no ponto central foi utilizado para melhor entendimento da influência dessas variáveis e de suas interações na síntese enzimática de monoglicerídeos. ${ }^{12}$ As sínteses foram realizadas em balões de fundo redondo de capacidade de $50 \mathrm{~mL}$ contendo $25 \mathrm{~mL}$ de misturas adequadas de glicerol e ácido láurico (razão molar glicerol/ ácido láurico entre 3:1 a 5:1) e após estabelecimento da temperatura do meio reacional no valor desejado $\left(45\right.$ a $65^{\circ} \mathrm{C}$ ), a preparação de lipase imobilizada mais eficiente foi adicionada numa proporção de $2 \% \mathrm{~m} / \mathrm{m}$ em relação à massa total de reagentes. Os experimentos foram efetuados de maneira randômica por um período máximo de 24 h sob agitação magnética de $200 \mathrm{rpm}$. Como variável resposta foi considerada a formação de monolaurina (\%). A análise estatística dos resultados foi realizada utilizando-se o programa STATGRAPHICS Plus versão 2.1 (StatPoint, Inc., Herndon, Virginia, USA). Um modelo polinomial foi ajustado por regressão linear pelo método dos mínimos quadrados aplicado aos resultados experimentais obtidos no planejamento fatorial, como representado na Equação 2.

$$
Y i=b o \sum_{i=1}^{n} b i X i+\sum_{i=1}^{n} b i i X i i+\sum_{i=1}^{n} \sum_{j=i+j}^{n} b i j X i X j
$$

em que $\mathrm{Y}_{\mathrm{i}}$ representa a variável resposta, $\mathrm{b}_{0}, \mathrm{~b}_{\mathrm{i}}, \mathrm{b}_{\mathrm{ii}}, \mathrm{b}_{\mathrm{ij}}$ representam os coeficientes da regressão, $X_{i}, X_{j}$ representam as variáveis estudadas.

\section{Quantificação dos produtos}

Para quantificação dos produtos formados (monolaurina, dilaurina e trilaurina), foi utilizado um cromatógrafo de fase gasosa (Varian - Modelo GC 3800), adaptado com uma coluna capilar CP Sil 5CB (Varian - $10 \mathrm{~m}$ x 0,25 mm x 0,12 $\mu \mathrm{m}$ ) e detector de ionização em chama (FID). As temperaturas do detector e injetor foram fixadas em $350{ }^{\circ} \mathrm{C}$. Nitrogênio foi usado como gás de arraste com split de 1:20. As rampas de temperatura da coluna foram variadas dependendo do método de análise utilizado, conforme metodologia descrita por Freitas et al. ${ }^{16}$

\section{RESULTADOS E DISCUSSÃO}

\section{Triagem da fonte de lipase}

O suporte POS-PVA previamente ativado com glutaraldeído foi utilizado para imobilizar preparações de lipases de diferentes fontes, mais especificamente, Candida antarctica $\mathrm{B}$ (Calb L), Thermomyces lanuginosa (Lipolase), Pseudomonas fluorescens (Lipase AK), Burkholderia cepacia (Lipase PS), Candida rugosa (LCR) e pâncreas de porco (LPP), obtendo-se derivados imobilizados com elevada atividade catalítica. Para evitar problemas de reversibilidade da reação, tomou-se cuidado especial para obter derivados imobilizados com teor de água inferior a $12 \%$. Nesta série de testes, lipase de Candida antarctica imobilizada em resina polimérica (Novozym 435) foi também usada para permitir uma comparação do desempenho dos sistemas imobilizados em POS-PVA.

Como os testes de triagem foram realizados com o objetivo de efetuar uma avaliação inicial da atividade de esterificação das diferentes fontes de lipases, as reações foram realizadas em condições fixas ( $2 \%$ $\mathrm{m} / \mathrm{m}$ de enzima imobilizada e substratos constituídos por uma mistura de glicerol/ ácido láurico numa razão molar de 3:1) que podem não representar a condição mais adequada para cada derivado imobilizado de lipase. Entretanto, permitiram verificar o comportamento da enzima no sistema reacional em função da estrutura de cada lipase 
testada, sem levar em consideração as interações complexas entre as variáveis que afetam a reação de esterificação mediada por lipases.

Os resultados obtidos para as lipases testadas são mostrados em conversão molar do ácido láurico em função do tempo (Figura 1) e as atividades de esterificação, produtividades e rendimentos são listados na Tabela 1 .

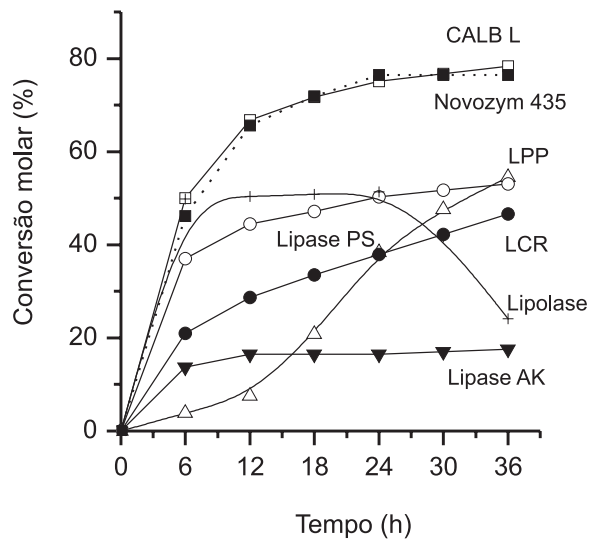

Figura 1. Perfil do consumo de ácido láurico ao longo da reação de esterificação com glicerol catalisada por diferentes preparações de lipase: Calb L-lipase de Candida antarctica B, Lipolase-lipase de Thermomyces lanuginosa, LPP - lipase de pâncreas de porco, LCR - lipase de Candida rugosa, Lipase AK-lipase de Pseudomonas fluorescens e Lipase PS - lipase de Burkholderia cepacia $\left(40-60^{\circ} \mathrm{C}\right.$, agitação magnética, reator fechado)

Tabela 1. Resumo dos experimentos realizados utilizando diferentes lipases imobilizadas

\begin{tabular}{lcccc}
\hline Sistema Imobilizado & $\mathrm{A}^{\mathrm{a}}$ & $\mathrm{P}^{\mathrm{b}}$ & $\mathrm{R}^{\mathrm{c}}$ & $\begin{array}{c}\text { Tempo } \\
(\mathrm{h})\end{array}$ \\
\hline Novozym 435 & 2,12 & 1,59 & 76,37 & 24 \\
Calb L & 2,17 & 1,08 & 78,19 & 36 \\
Lipolase & 2,14 & 1,07 & 51,53 & 24 \\
Candida rugosa & 1,29 & 0,65 & 46,50 & 36 \\
Lipase Pancreática & 1,52 & 0,76 & 54,41 & 36 \\
AK “Amano” 20 & 0,49 & 0,24 & 18,48 & 36 \\
PS “Amano" & 1,47 & 0,74 & 53,00 & 36
\end{tabular}

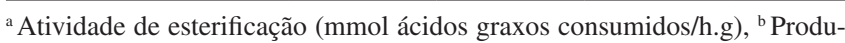
tividade (mmol ácidos graxos consumidos/h), ${ }^{\mathrm{c}}$ Rendimento por massa de catalisador (mmol ácidos graxos consumidos/g), ${ }^{\mathrm{d}}$ Tempo no qual foi obtido a maior conversão molar.

Verifica-se na Figura 1 que todas as lipases testadas foram capazes de formar acilgliceróis. No entanto, a conversão molar do ácido láurico foi dependente da fonte de lipase testada, sugerindo diferentes afinidades das lipases pelo substrato. Entre as lipases imobilizadas em POS-PVA, a lipase Calb L resultou na conversão molar mais elevada (78\%), similar à alcançada pela preparação comercial Novozym 435. Ambas lipases são de Candida antarctica, evidenciando, desta forma, a compatibilidade do suporte para imobilizar a lipase Calb L, como constatado anteriormente para as outras fontes de lipases. ${ }^{17,18}$

Verifica-se que o perfil de consumo do ácido láurico pela atuação da lipase de Candida antarctica está de acordo com suas propriedades e a localização do sítio ativo em forma de funil, numa região da enzima, com diversos resíduos de aminoácidos atuando através da formação de cavidade com características aniônicas, denominada de "cavidade do oxiânion" ${ }^{19}$ Essa lipase apresenta importante seletivi- dade em reações com álcoois secundários ${ }^{20,21} \mathrm{e}$ ausência de ativação interfacial, catalisando muito lentamente a hidrólise de triglicerídeos de cadeia longa. Por esta razão, é classificada por alguns autores como uma esterase. Entretanto, essa lipase atua muito bem em substratos que contenham ácidos graxos de cadeia média como, por exemplo, o ácido láurico $\left(\mathrm{C}_{12}\right) \cdot{ }^{22}$

Com relação às lipases de Pseudomonas fluorescens (lipase AK) e Burkholderia cepacia (lipase PS) apesar das estruturas similares e sítios ativos com conformidades tridimencionais semelhantes, ${ }^{23}$ os resultados obtidos sugerem diferentes especificidades dessas enzimas para o ácido láurico. Burgess e Jennings ${ }^{24}$ propuseram que a lipase de Pseudomonas fluorescens possui sítio ativo plano, dentro de uma cavidade, composto por sequências de resíduos importantes para ação catalítica, sugerindo uma atuação preferencial na resolução de moléculas insaturadas lineares justificando, desta forma, o baixo rendimento $(18,3 \%)$ alcançado por esta preparação de lipase na reação de esterificação empregando o ácido láurico. Por outro lado, a lipase de Burkholderia cepacia necessita de uma interface adequada (ativação interfacial) para que ocorra uma melhor interação entre enzima e substrato, situação inexistente no meio reacional testado em função da menor hidrofobicidade do ácido láurico em relação a um triglicerídeo, substrato ideal para atuação da lipase PS..$^{25}$

Embora o derivado imobilizado de lipase pancreática tenha apresentado menor velocidade reacional em relação à lipase de Burkholderia cepacia (lipase PS), ambas alcançaram ao final de 36 $\mathrm{h}$ o mesmo valor de conversão molar (55\%). Dados encontrados na literatura referentes ao emprego da lipase pancreática em reações de esterificação são escassos, ${ }^{17}$ no entanto, esta preparação pode ser uma opção interessante por apresentar um custo bem inferior quando comparado às outras lipases. Destaca-se que as preparações de lipases pancreáticas são geralmente impuras, por serem normalmente isoladas de pâncreas ou biles de animais (porco), entretanto, essa particularidade não é restritiva para condução de reações em meio orgânico.

As preparações de Lipolase e Candida rugosa imobilizadas em POS-PVA não apresentaram desempenhos satisfatórios, sendo constatadas conversões máximas de ácido láurico, respectivamente, de 50 e $47 \%$. Além do baixo desempenho, a Lipolase apresentou suscetibilidade de reversão da reação de forma bem acentuada, ocorrendo um decaimento na conversão molar após $24 \mathrm{~h}$ de processo. Esse desempenho pode estar associado ao fato da lipase de Thermomyces lanuginosa necessitar de grandes mudanças conformacionais na região da "tampa" para interagir com os diferentes tipos de substratos, situação essa desfavorável em meio orgânico, que torna a estrutura da lipase mais rígida e dificulta sua flexibilidade, resultando em menores conversões. ${ }^{26}$ Apesar da Lipolase ser mais utilizada na formulação de detergentes, ${ }^{27}$ alguns trabalhos descritos na literatura indicam sua aplicabilidade na síntese de monoésteres (biodiesel) ${ }^{28}$

A baixa conversão molar (47\%) obtida pela lipase de Candida rugosa pode ser associada com sua estrutura tridimensional. Esta lipase possui um sítio ativo posicionado em um longo túnel na parte interna da proteína, com uma larga área disponível para a ligação da cadeia do ácido graxo, mostrando uma preferência por ácidos graxos de cadeia curta e média, principalmente entre $\mathrm{C}_{4} \mathrm{a} \mathrm{C}_{10}$. Esta restrição interfere na atuação dessa lipase em substratos (em meio orgânico) contendo mais de 12 carbonos, ${ }^{29}$ como no sistema reacional utilizado neste trabalho (substrato contendo 15 carbonos $=12 \mathrm{C}$ ácido láurico + 3C glicerol). Em meio aquoso essa limitação não é observada, sendo inclusive uma das lipases recomendadas para hidrólise total de triglicerídeos por não apresentar regioespecificidade. ${ }^{30}$

De acordo com os resultados obtidos e sumarizados na Tabela 1, verifica-se que nas condições testadas a lipase Calb L foi o biocatalisador mais eficiente na síntese de laurato de glicerila sendo, 
portanto, selecionado para testes subsequentes. Resultados similares foram descritos por Monteiro et al., ${ }^{31}$ em testes realizados com a lipase Novozym 435 na presença de dois solventes de polaridades diferentes (hexano e 1,4-dioxano, à $40^{\circ} \mathrm{C}$ ), obtendo-se uma mistura de mono e dilaurina, em ambos sistemas reacionais.

\section{Planejamento de experimentos}

Por meio da ferramenta do planejamento experimental, buscou-se determinar os efeitos das variáveis: temperatura $\left(\mathrm{x}_{1}\right)$ e razão molar entre glicerol e ácido láurico $\left(\mathrm{x}_{2}\right)$ na formação de monolaurina. Todos os experimentos foram efetuados empregando-se $2 \%(\mathrm{~m} / \mathrm{m})$ de lipase Calb L imobilizada em POS-PVA. A composição da mistura de glicerídeos obtida para cada condição ensaiada, mostrada na Figura 2 , indica que a reação foi direcionada para formação preferencial de monolaurina e dilaurina, sendo detectados apenas traços de trilaurina $(<0,16 \%)$. A matriz proposta, juntamente com os resultados obtidos para a formação de monolaurina (\%), é mostrada na Tabela 2.

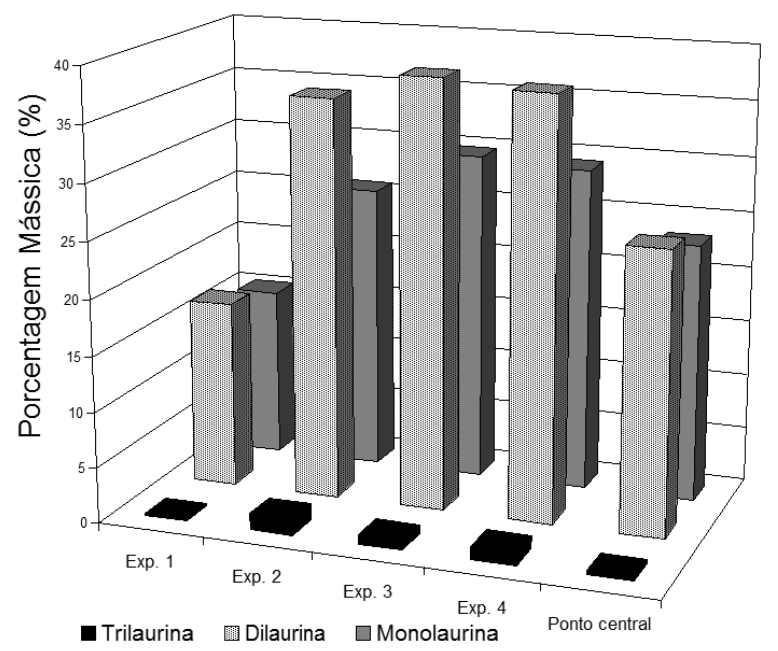

Figura 2. Distribuição dos produtos formados nas reações de esterificação do glicerol com ácido láurico catalisada pela lipase Calb L imobilizada em POS$P V A$, nas diferentes condições ensaiadas no planejamento de experimentos

Tabela 2. Matriz do planejamento fatorial completo $2^{2}$ e resultados obtidos

\begin{tabular}{cccccc}
\hline Ensaio & $\begin{array}{c}\text { Valores } \\
\text { codificados }\end{array}$ & \multicolumn{3}{c}{ Valores reais } & $\begin{array}{c}\text { Variável } \\
\text { resposta }\end{array}$ \\
\hline & & & $\begin{array}{c}\text { Temperatura } \\
\left({ }^{\circ} \mathrm{C}\right)\end{array}$ & $\begin{array}{c}\text { Razão molar } \\
\text { (glicerol: ácido } \\
\text { láurico) }\end{array}$ & $\begin{array}{c}\text { Monolaurina } \\
(\%)\end{array}$ \\
1 & - & - & 45 & $1: 1$ & 15,31 \\
2 & + & - & 65 & $1: 1$ & 25,80 \\
3 & - & + & 45 & $5: 1$ & 29,66 \\
4 & + & + & 65 & $5: 1$ & 29,19 \\
5 & 0 & 0 & 55 & $3: 1$ & 23,00 \\
6 & 0 & 0 & 55 & $3: 1$ & 22,01 \\
\hline
\end{tabular}

Verifica-se que, para os ensaios efetuados com substratos contendo relação equimolar de reagentes (ensaios 1 e 2), o aumento da temperatura de 45 para $65^{\circ} \mathrm{C}$ promoveu um acréscimo substancial na formação de monolaurina passando de teores da ordem de 15,31 para $25,80 \%$. Por outro lado, utilizando substratos com excesso de glicerol (5:1), ensaios 3 e 4, a formação de monolaurina foi independente da temperatura de incubação utilizada. De maneira geral, a formação de monolaurina foi favorecida para meios reacionais contendo excesso de glicerol para uma ampla faixa de temperatura $\left(45\right.$ a $\left.65^{\circ} \mathrm{C}\right)$.

A Tabela 3 reúne os dados da análise dos efeitos, erros-padrão e do teste t de Student's. Dentro da região analisada, verifica-se que apenas a razão molar $\left(\mathrm{x}_{2}\right)$ apresentou influência significativa em nível de $90 \%$ de confiança. Entretanto, por meio de uma análise minuciosa pode-se observar que tanto os efeitos da variável $\left(\mathrm{x}_{1}\right)$ como da interação da temperatura e razão molar $\left(\mathrm{x}_{1} \mathrm{x}_{2}\right)$ apresentaram valores similares $(2,50$ e 2,74) e próximos da significância. Assim, objetivando-se um melhor ajuste do modelo aos dados experimentais, optou-se pela manutenção dos coeficientes correspondentes a estes efeitos na equação matemática que representa o processo na região experimental estudada.

Tabela 3. Estimativas dos efeitos, erros padrão e teste t de Student`s para a produção de monolaurina de acordo com o planejamento fatorial $2^{2}$

\begin{tabular}{lcccc}
\hline Variáveis & Efeitos & Erro-padrão Valores de $\mathrm{t}$ & $p$ \\
\hline Média & 24,16 & $\pm 0,85$ & 28,34 & 0,001 \\
Temperatura $\left(\mathrm{x}_{1}\right)$ & 2,50 & $\pm 1,04$ & 2,40 & 0,138 \\
Razão molar $\left(\mathrm{x}_{2}\right)$ & 4,44 & $\pm 1,04$ & 4,24 & $0,051^{*}$ \\
Interação $\mathrm{x}_{1} \mathrm{x}_{2}$ & $-2,74$ & $\pm 1,04$ & $-2,62$ & 0,119 \\
\hline
\end{tabular}

$* \mathrm{p}<0,10 ; \mathrm{R}^{2}=0,9388$

Os dados obtidos para a concentração de monolaurina foram ajustados por análise de regressão múltipla para um modelo linear e a melhor função ajustada pode ser demonstrada pela Equação 3.

$y=24,16+2,51 x_{1}+4,43 x_{2}-2,74 x_{1} x_{2}$

em que: y é a variável resposta e $\mathrm{x}_{1}$ e $\mathrm{x}_{2}$ representam as variáveis estudadas para temperatura e razão molar, respectivamente.

A validade do modelo proposto foi verificada por meio da análise de variância (Tabela 4), na qual se constatou que a regressão obtida foi estatisticamente significativa $(\mathrm{p}<0,10)$, apresentando um coeficiente de determinação $\left(\mathrm{R}^{2}\right)$ de 0,9387 , indicando que o modelo pode explicar $93,87 \%$ da variabilidade dos resultados experimentais obtidos.

Tabela 4. Análise de Variância para o ajuste do modelo proposto que representa a formação de monolaurina a partir da esterificação do glicerol com ácido láurico

\begin{tabular}{lccccc}
\hline $\begin{array}{l}\text { Fonte de } \\
\text { variação }\end{array}$ & $\begin{array}{c}\text { Soma } \\
\text { quadrática }\end{array}$ & $\begin{array}{c}\text { Graus de } \\
\text { liberdade }\end{array}$ & $\begin{array}{c}\text { Média } \\
\text { quadrática }\end{array}$ & F & $p$ \\
\hline Modelo & 133,81 & 3 & 44,60 & 10,23 & $0,09 *$ \\
Resíduo & 8,72 & 2 & 4,36 & & \\
Erro total & 142,53 & 5 & & & \\
\hline
\end{tabular}

$* \mathrm{p}<0,10 ; \mathrm{R}^{2}=0,9388$

Os valores preditos pelo modelo matemático representado na superfície de resposta (Figura 3), indicam que a concentração máxima de monolaurina pode ser obtida em temperatura entre 45 e $65^{\circ} \mathrm{C}$ e razão molar de 5:1 entre glicerol/ácido láurico, sendo selecionada como ótima a condição de menor temperatura (ensaio 3). Reações de esterificação do glicerol com ácido láurico nas condições selecionadas foram efetuadas e o perfil de formação de monolaurina confirmou o modelo matemático, sendo obtido $31,35 \%$ de monolaurina, valor próximo ao predito (Figura 4). 
Esses resultados sugerem que o delineamento experimental constituiu apenas uma etapa no processo de otimização da formação de monolaurina, sendo ainda necessários estudos adicionais para determinar outros parâmetros da reação como, por exemplo, a influência da massa de biocatalisador na síntese de monolaurina.

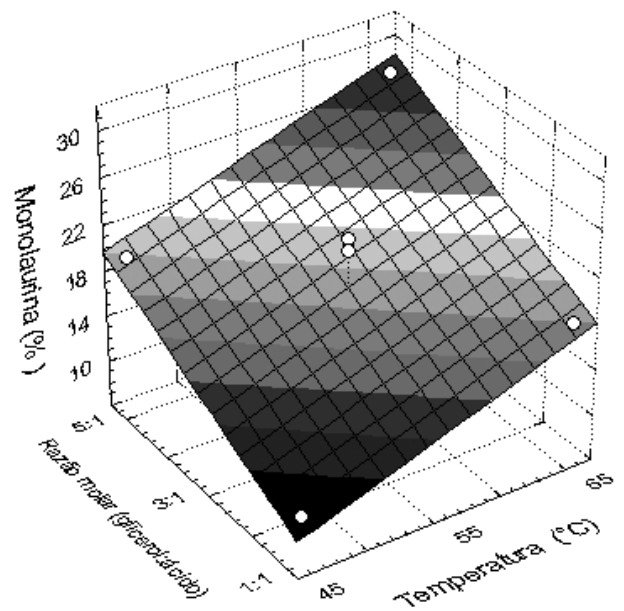

Figura 3. Superfície de resposta para a produção de monolaurina na esterificação do glicerol com ácido láurico empregando lipase Calb L imobilizada em POS-PVA, descrita pela Equação 2

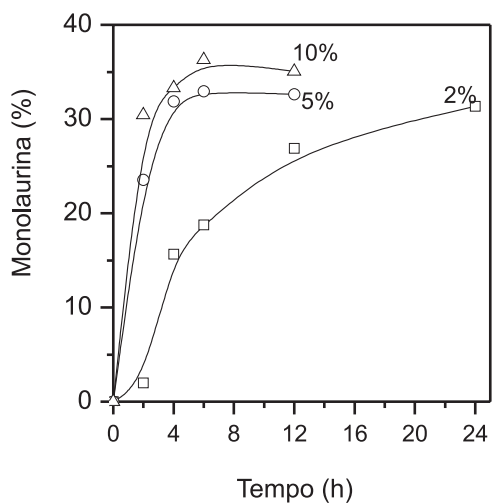

Figura 4. Perfil de formação de monolaurina empregando-se 2, 5 e $10 \% \mathrm{~m} / \mathrm{m}$ de lipase Calb L imobilizada em POS-PVA na reação de esterificação do glicerol com ácido láurico (razão molar $=5: 1$ entre glicerol: ácido láurico) $a 45^{\circ} \mathrm{C}$

Desta forma, experimentos adicionais foram ainda realizados variando a massa de biocatalisador entre 2 a 10\% em relação à massa total de reagentes envolvidos na reação. Os resultados (Figura 4) indicam que a concentração de enzima afetou acentuadamente a velocidade inicial da reação, sendo alcançadas frações molares de monolaurina entre 33 a $36 \%$ em apenas $6 \mathrm{~h}$, para reações catalisadas com 5 e $10 \%$ de biocatalisador. Esse incremento corresponde uma redução da ordem de 4 vezes no tempo originalmente necessário para atingir o equilíbrio da reação.

\section{CONCLUSÃO}

Entre cinco preparações de lipases, o derivado imobilizado da lipase Calb L em POS-PVA mostrou-se mais eficiente para catalisar a esterificação do glicerol com ácido láurico, obtendo elevada conversão molar do ácido láurico e formação de $21 \% \mathrm{~m} / \mathrm{m}$ de monolaurina. A otimização da reação permitiu prever as condições necessárias que favorecem o alcance de elevadas concentrações de monolaurina, sendo a reação maximizada $(31,35 \%$ de produto) para meios reacionais constituídos de glicerol e ácido láurico numa razão molar de 5:1 e temperatura de incubação de $45^{\circ} \mathrm{C}$, por um período de incubação de $24 \mathrm{~h}$. A fração molar de monolaurina pode ser ainda incrementada pela utilização de concentrações mais elevadas de biocatalisador.

\section{REFERÊNCIAS}

1. Da Silva, M. A. M.; Medeiros, V. C.; Freire, D. M. G.; Langone, M. A. P.; Congresso Brasileiro de Engenharia Química, Natal, Brasil, 2002.

2. Machado, M. D.; Perez-Pariente, J; Sastre, E.; Cardoso, D.; De Guerene, A. M.; Appl. Catal. A 2000, 203, 321.

3. Sonntag, N. O. V.; J. Am. Oil Chem. Soc. 1982, 59, 795.

4. H-Kittikun, A.; Kaewthong, W.; Cheirsilp, B.; Biochem. Eng. J. 2008, 40, 116.

5. Pawongrat, R.; Xu, X.; H-Kittikun, A.; Food Chem. 2007, 104, 251.

6. Börjesson, I. E.; Härröd, M.; J. Am. Oil Chem. Soc. 1991, 76, 701.

7. Mota, C. J. A.; Da Silva, C. X. A.; Gonçalves, V. L. C.; Quim. Nova 2009, 32, 639

8. http://www.heranswer.com/monolaurin.asp, acessada em Outubro 2009.

9. Lieberman, S.; Enig, M.G.; Preuss, H.G.; Alternative \& Complementary Therapies 2006, 12, 310 .

10. http://www.aromalandia1.hpg.ig.com.br/Aromalandia_informativo_1_ abril2003.pdf, acessada em Outubro 2009.

11. Yahya, A. R. M.; Anderson, W. A.; Moo-Young, M.; Enzyme Microb. Technol. 1998, 23, 438.

12. Box, G. E. P.; Hunter, W. G.; Hunter, J. S.; Statistics for Experimenters: An Introduction to Design, Wiley \& Sons Inc: New York, 1978.

13. Paula, A. V.; Moreira, A. B. R.; Braga, L. P.; Bruno, L. M.; Castro, H. F.; Quim. Nova 2008, 31, 35 .

14. Pencreac'h, G.; Baratti, J. C.; Enzyme Microb. Technol. 1996, 18,417.

15. Ferreira Dias, S.; Fonseca, M. M. R.; Biotechnol. Tech. 19993, 7, 447.

16. Freitas, L.; Perez, V. H.; Santos, J. C.; Castro, H. F.; J. Braz. Chem. Soc. 2007, 18, 1360

17. Paula, A. V.; Urioste, D.; Santos, J. C.; Castro, H. F.; J. Chem. Technol. Biotechnol. 2007, 82, 281.

18. Moreira, A. B. R.; Pérez, V. H.; Zanin, G. M.; Castro, H. F.; Energy Fuels 2007, 21, 3689

19. Schrag, J. D.; Li, Y.; Cygler, M.; Lang, D.; Burgdorf, T.; Hecht, H. J.; Schmid, R.; Schomburg, D.; Rydel, T. J.; Oliver, J. D.; Strickland, L. C.; Dunaway, C. M.; Larson, S.B.; Day, J.; McPherson; A.; Structure 1997, 15, 187.

20. Ottosson, J.; Hult, K.; J. Mol. Catal. B: Enzym. 2001, 4, 1025.

21. Raza, S.; Fransson, L.; Hult, K.; Protein Sci. 2001, 10, 329.

22. Pleiss, J.; Fischer, M.; Schmid, R. D.; Chem. Phys. Lipids 1998, 93, 67.

23. Kojima, Y.; Shimizu, S.; J. Biosci. Bioeng. 2003, 96, 219.

24. Burgess, K.; Jennings, L. D.; J. Am. Oil Chem. Soc. 1991, 113, 6129.

25. Kim, K. K.; Song, H. K.; Shin, D. H.; Hwang, K. Y.; Suh, S. W.; Structure $1997,5,173$.

26. Salis, A.; Svenssonb, I.; Monduzzia, M.; Solinasa, V.; Adlercreutzb, P.; Biochim. Biophys. Acta 2003, 1646, 145.

27. Aaslyng, D.; Gormsen, E.; Malmos, H.; J. Chem. Technol. Biotechnol. 1991, 50, 321

28. Costa Neto, P. R.; Tese de Doutorado, Universidade Federal de Santa Catarina, Brasil, 2002.

29. Pereira, E. B.; Castro, H. F.; Moraes, F. F.; Zanin, G. M.; Appl. Biochem. Biotechnol. 2001, 91-3, 739.

30. Rooney, D.; Weatherley, L. R.; Process Biochem. 2001, 36, 947.

31. Monteiro, J. B.; Ninow, J. L.; Nascimento, M. G.; V Seminário de Hidrólise Enzimática e Biocatálise, Maringá, Brasil, 1996. 